\begin{tabular}{|c|c|c|}
\hline & $\begin{array}{l}\text { European Association for the } \\
\text { Development of Renewable Energies, Environment } \\
\text { and Power Quality (EA4EPQ) }\end{array}$ & $\begin{array}{c}\text { International Conference on Renewable Energies and Power Quality } \\
\text { (ICREPQ'12) } \\
\text { Santiago de Compostela (Spain), 28th to 30th March, } 2012\end{array}$ \\
\hline
\end{tabular}

\title{
Analysis of Generalized Non-Active Power Theory for Compensation of Non- Periodic Disturbances
}

\author{
Josef Tlusty ${ }^{*}$, Jan Svec ${ }^{*}$, Josep Balcells Sendra ${ }^{* *}$ and Viktor Valouch ${ }^{+}$ \\ *Department of Electric Power Engineering \\ Faculty of Electrical Engineering, CTU \\ Prague, Czech Republic \\ E-mail: tlusty@fel.cvut.cz; jan.svec@fel.cvut.cz \\ ${ }^{* *}$ Department of Electronic Engineering \\ Universitat Politècnica de Catalunya \\ Terrassa, Spain \\ E-mail: balcells@eel.upc.es
}

\author{
${ }^{+}$Institute of Thermomechanics \\ Academy of Sciences of the Czech Republic \\ Prague, Czech Republic \\ E-mail: valouch@it.cas.cz
}

\begin{abstract}
The principle and analysis of usage of the generalized non-active power theory for the parallel compensation of periodic and non-periodic current disturbances is presented in the paper. A non-linear unbalanced load generating periodic as well as non-periodic stochastic currents connected to an unsymmetrical non-sinusoidal voltage source is considered.
\end{abstract}

\section{Key words}

Generalized non-active power theory, electric power system, parallel compensation, non-periodic disturbances, averaging time interval, simulation

\section{Introduction}

The importance of the problems related to the presence of distorted waveforms in electrical systems has been pointed out since the early thirties, when two important electric power theories were formulated by Fryze and Budeanu in 1927, 1932, respectively.

In 1984, the IRP (Instantaneous Reactive Power) theory, called also $\mathrm{p}-\mathrm{q}$ theory, was first published in English [1], giving a tool to compensate for the whole reactive power and the fluctuating instantaneous active power produced by a nonlinear load.

It has been mathematically as well as in some experiments proofed by many authors that under asymmetrical voltage system the IRP theory is not able to produce the sinusoidal currents of the system [2]. Thus, several modifications, like the vectorial theory [3], d-q theory [4], or the p-q-r theory [5] have been suggested to improve the IRP theory. The original IRP theory and its modifications were formulated in the time domain, so they have been the mostly used theories for proposing compensation control algorithms of active and hybrid power filters working in the real time.
Although some applications of the CPC (Current Physical Components) or FBD (Fryze - Buchholz Depenbrock) theories as the theoretical tools for generating reference signals for compensating devices were reported [6]-[8] as well, the IRP theory and its modifications still remain prevailing ones for these purposes. The main reason is that these theories are based on the time domain approach, what makes their implementation easier and more straightforward then in case of the CPC and FBD theories.

The power theories mentioned above have been mostly discussed, classified and compared in terms of their capabilities for the compensation of unwanted instantaneous power components in three-phase asymmetrical systems with non-sinusoidal, but periodic, voltages and currents.

Although several different approaches have been focused on non-periodic (subharmonic, interharmonic) voltage and current components identification [9]-[15] as well, the purpose was mainly to model or detect these disturbance waveforms for estimation of power quality indices.

But now, the compensation of subharmonic, nonperiodic, and stochastic disturbances in the electric power systems has emerged as a very serious problem to be solved. The diversity of the features of these disturbances makes their compensation quite difficult. The compensation devices based on power electronics converters must work in the real time, so the time domain approach to control algorithms for the compensation of non-periodic disturbances seems to be promising.

In the Fryze's theory the active power $P$ was calculated as the average value of $p=v i$ over one fundamental cycle $T=1 / f$. The active current $i_{\mathrm{a}}$ over this period was then the replica of the voltage $v$, related to the voltage by the conductance $G=P / V^{2}$, where $V^{2}$ was again calculated as the average value of $v^{2}$ over the same cycle. A serious 
limitation, especially in accordance with problems related to the compensation of non-periodic and stochastic disturbances, is that the calculation of $i_{\mathrm{a}}$ is characterized by the time delay $T$.

The original Fryze's theory of the non-active current is extended in [16] by using a general averaging time interval $T_{\mathrm{C}}$ that can be chosen either one-half fundamental cycle, one full fundamental cycle $T$, that is the same as that in Fryze's theory, or multiple fundamental cycles, depending on the character of the load current, compensation objectives and the energy storage capacity of a power electronics-based compensator.

A principal and analysis of usage of this GNP (Generalized Non-active Power) theory for the parallel compensation of periodic and non-periodic disturbances is presented in the paper. A non-linear unbalanced load generating periodic as well as non-periodic stochastic currents connected to an unsymmetrical non-sinusoidal voltage source is considered.

\section{Generalized non-active power theory}

For the three-phase system, the voltage and current vectors may be expressed as follows

$$
\begin{aligned}
& \boldsymbol{v}=\left[v_{\mathrm{a}}, v_{\mathrm{b}}, v_{\mathrm{c}}\right]^{\mathrm{T}} \\
& \boldsymbol{i}=\left[i_{\mathrm{a}}, i_{\mathrm{b}}, i_{\mathrm{c}}\right]^{\mathrm{T}}
\end{aligned}
$$

The active current is defined in this generalized nonactive power theory by

$$
\begin{gathered}
i_{\mathrm{a}}(t)=\frac{P(t)}{V_{\mathrm{P}}^{2}(t)} \boldsymbol{v}_{\mathrm{P}}(t)=Y(t) \boldsymbol{v}_{\mathrm{P}}(t) \\
P(t)=\frac{1}{T_{\mathrm{C}}} \int_{t-T_{\mathrm{C}}}^{t} \boldsymbol{v}^{\mathrm{T}}(\tau) \boldsymbol{i}(\tau) \mathrm{d} \tau \\
V_{\mathrm{P}}^{2}(t)=\frac{1}{T_{\mathrm{C}}} \int_{t-T_{\mathrm{C}}}^{t} \boldsymbol{v}_{\mathrm{P}}^{\mathrm{T}}(\tau) \boldsymbol{v}_{\mathrm{P}}(\tau) \mathrm{d} \tau
\end{gathered}
$$

where $v_{\mathrm{P}}(t)$ is the reference voltage vector.

The non-active current is the remaining part of the current vector

$$
\boldsymbol{i}_{\mathrm{n}}(t)=\boldsymbol{i}(t)-\boldsymbol{i}_{\mathrm{a}}(t)
$$

If the current $\boldsymbol{i}(t)$ is the current of an unbalanced load, which may contain, in general, harmonic and also nonperiodic or stochastic components, and the current $\boldsymbol{i}_{\mathrm{a}}(t)$ is the demanded source current, then $i_{\mathrm{n}}(t)$ is the current that should be injected by a parallel compensator connected to the PCC (Point of Common Coupling).

By choosing $T_{\mathrm{C}} \rightarrow 0$, the GNP theory gives the same results as those obtained by using the well known IRP theory. If $T_{\mathrm{C}} \rightarrow \infty$, the non-active component in the nonperiodic load current is completely eliminated, so the source current is only active.

\section{Analysis of GNP theory}

It was shown [17] that the precision of the calculation of the currents $\boldsymbol{i}_{\mathrm{a}}, \boldsymbol{i}_{\mathrm{n}}$ by using (2), (5) in unbalanced nonsinusoidal systems with non-periodic load currents is sufficient if $T_{\mathrm{C}}$ is chosen to be 5-10 times that of the fundamental period. Let us demonstrate some basic attributes of the GNP theory on an example of the one phase voltage and current

$$
v=\sqrt{2} V \sin \omega t
$$

$$
\begin{aligned}
& i=\sqrt{2} I(1+\Delta \sin \Delta \omega t) \sin \omega t+\sqrt{2} I_{\mathrm{h}} \sin \omega_{\mathrm{h}} t= \\
& =(\sqrt{2} I+\sqrt{2} \Delta I \sin \Delta \omega t) \sin \omega t+\sqrt{2} I_{\mathrm{h}} \sin \omega_{\mathrm{h}} t= \\
& =\sqrt{2} I \sin \omega t+i_{\mathrm{np}}+i_{\mathrm{h}}
\end{aligned}
$$

The current contains three components: the fundamental, non-periodic (specifically subharmonic here), and harmonic one.

By using the concept of the GNP theory (2) - (4), the respective active current can be expressed as follows

$$
i_{\mathrm{a}}=Y v=\sqrt{2} I \sin \omega t+i_{2}+i_{\text {anp }}+i_{\text {ah }}
$$

where the expressions for the components are presented in the Appendix. If $T_{\mathrm{C}}=k T / 2, k=1,2,3 \ldots$, the current component $i_{2}$ is equal to zero. By changing the value of $T_{\mathrm{C}}$ we can evaluate how the components $i_{\text {anp }}, i_{\text {ah }}$ are more or less excluded from the active current component $i_{\mathrm{a}}$. As it has been already said, for $T_{\mathrm{C}} \gg T$ these two components are almost completely suppressed and we can get the active current practically in the correct form $i_{\mathrm{a}}=\sqrt{2} I \sin \omega t$.

After some manipulations, the equation (D3) for $i_{\text {ah }}$ in Appendix can be expressed as

$$
i_{\mathrm{ah}}=\frac{\sqrt{2} I_{\mathrm{h}}}{2}\left[\begin{array}{l}
G_{\mathrm{h}}{ }^{+} \sin \left(\omega_{\mathrm{h}} t-\phi_{\mathrm{h}}{ }^{+}\right)+G_{\mathrm{h}}{ }^{-} \sin \left(\omega_{\mathrm{h}} t-\phi_{\mathrm{h}}{ }^{-}\right)- \\
-G_{\mathrm{h}}{ }^{+} \sin \left(\left(\omega_{\mathrm{h}}+2 \omega\right) t-\phi_{\mathrm{h}}{ }^{+}\right)- \\
-G_{\mathrm{h}}{ }^{-} \sin \left(\left(\omega_{\mathrm{h}}-2 \omega\right) t-\phi_{\mathrm{h}}{ }^{-}\right)
\end{array}\right]
$$

where

$$
\begin{aligned}
& G_{\mathrm{h}}{ }^{+}=\sin \phi_{\mathrm{h}}{ }^{+} / \phi_{\mathrm{h}}{ }^{+}, \phi_{\mathrm{h}}{ }^{+}=\left(\omega_{\mathrm{h}}+\omega\right) T_{C} / 2 \\
& {G_{\mathrm{h}}}^{-}=\sin \phi_{\mathrm{h}}{ }^{-} / \phi_{\mathrm{h}}{ }^{-}, \phi_{\mathrm{h}}{ }^{-}=\left(\omega_{\mathrm{h}}-\omega\right) T_{C} / 2
\end{aligned}
$$

We see that, in addition to the presence of the component with the frequency $\omega_{\mathrm{h}}$, two more components with frequencies $\left(\omega_{\mathrm{h}}+2 \omega\right),\left(\omega_{\mathrm{h}}-2 \omega\right)$ have appeared in the spectrum of $i_{\text {ah }}$ after processing the current $i$ (7) in (2).

By using formulas (9)-(10), we can analyze how the current component with the frequency $\omega_{\mathrm{h}}$, which is present in the load current $i_{\mathrm{L}}$, will appear in the active current $i_{\mathrm{La}}$ when the GNP theory is applied. Let us suppose that the frequency $\omega_{\mathrm{h}}$ is not only an integer multiple of the fundamental frequency $\omega$ (harmonic component), but generally any other one, that is subharmonic $\langle 2 \pi 1,2 \pi 49 \mathrm{~Hz}>$, harmonic $(2 \pi h 50 \mathrm{~Hz}, h=1$, 
$2,3, \ldots)$ or interharmonic higher than $2 \pi 50 \mathrm{~Hz}$. The thing is that these non-periodic components with frequencies different from integer multiples of the fundamental frequency $\omega$ and their possible compensation are of great interest today.

Fig. 1 shows the impact of the value of $T_{\mathrm{C}}$ on the rate $I_{\mathrm{La}} / I_{\mathrm{L}}$ for different frequencies, where $I_{\mathrm{La}}, I_{\mathrm{L}}$ are the respective magnitudes of the current components presented in $i_{\mathrm{La}}(t), i_{\mathrm{L}}(t)$ (for $i_{\mathrm{La}}$ given by the first two terms in (9)). We see that all harmonics presented in $i_{\mathrm{L}}(t)$ are completely suppressed for $T_{\mathrm{C}}$ being one full fundamental cycle $T$ or any multiple fundamental cycles. We see that components of interharmonic frequencies are substantially suppressed as well. As for the subharmonic frequencies we can estimate the degree of the suppression of these components too. For example, if the magnitude of the load current fluctuates with the frequency $15 \mathrm{~Hz}$, the current components of frequencies $35,65 \mathrm{~Hz}$, in addition to the component of the fundamental frequency $50 \mathrm{~Hz}$, are presented in this current. These components remain in the spectrum of the current $i_{\mathrm{La}}$, but their magnitudes are mitigated, for example, only to 18.7 and $24.4 \%$ (for $T_{\mathrm{C}}=$ $5 T=0.1 \mathrm{~s}$, two greatest side lobes at the green line in Fig. 1) of those presented in the load current $i_{\mathrm{L}}$.

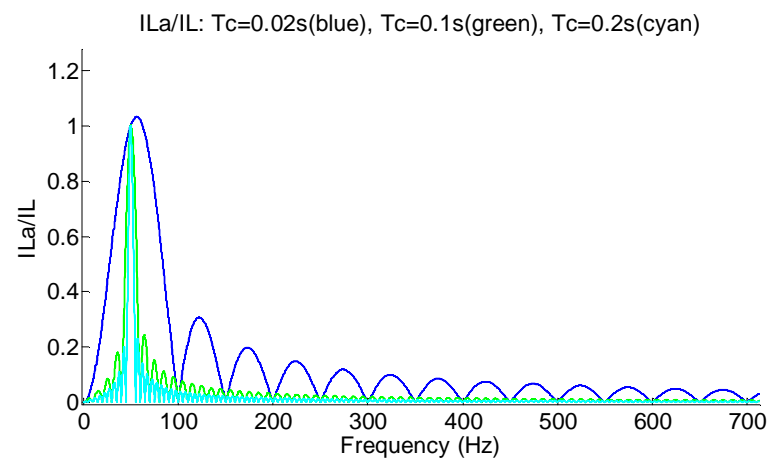

a)

ILa/IL: Tc=0.02s(blue), Tc=0.1s(green), Tc=0.2s(cyan)

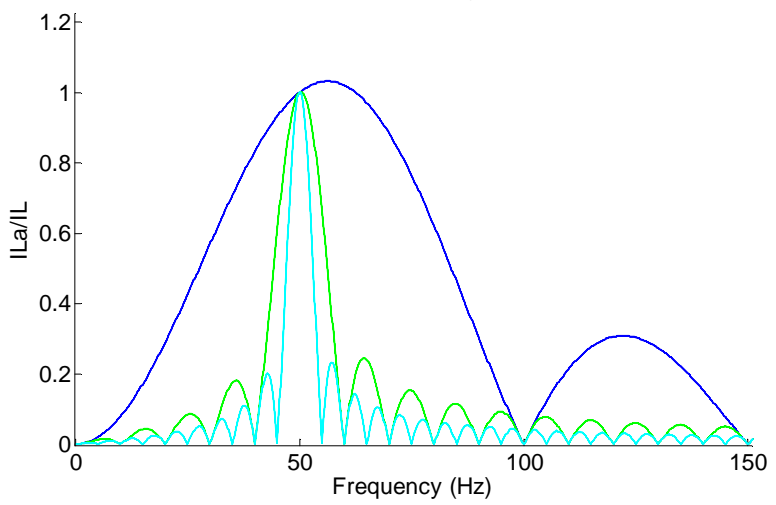

b)

Fig. 1. Impact of value of $T_{\mathrm{C}}$ on rate $I_{\mathrm{La}} I_{\mathrm{L}} ;$ a) for frequencies in range $<0,700 \mathrm{~Hz}>$; b) zoom of part a)

Figs. 2, 3 show similar dependences of the terms $G_{\mathrm{h}}{ }^{+}$, $G_{\mathrm{h}}{ }^{-}$(10) characterizing the magnitudes of two further components with frequencies $\left(\omega_{\mathrm{h}}+2 \omega\right),\left(\omega_{\mathrm{h}}-2 \omega\right)$ which are pronounced, according to (9), in the spectrum of $i_{\mathrm{La}}$ as well. It is evident that $G_{\mathrm{h}}{ }^{+}=G_{\mathrm{h}}{ }^{-}=0$ for the frequencies being integer multiples of the fundamental frequency. Therefore these two additional components are zero for harmonic frequencies too.

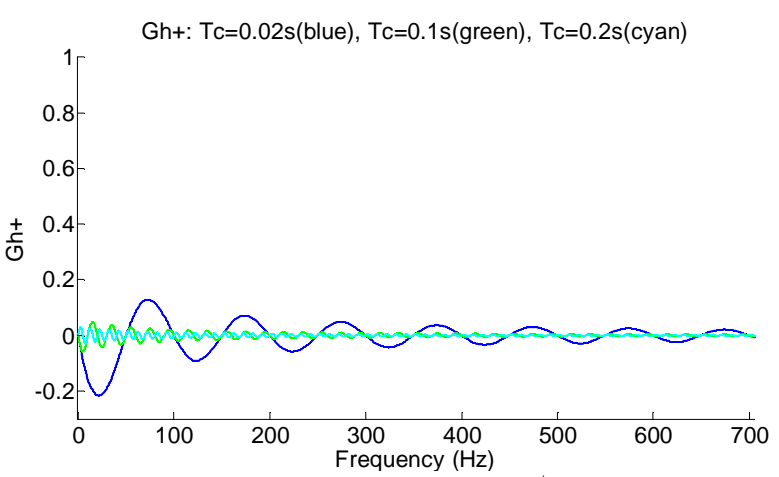

Fig. 2. Impact of value of $T_{\mathrm{C}}$ on rate $G_{h}{ }^{+}$for different frequencies

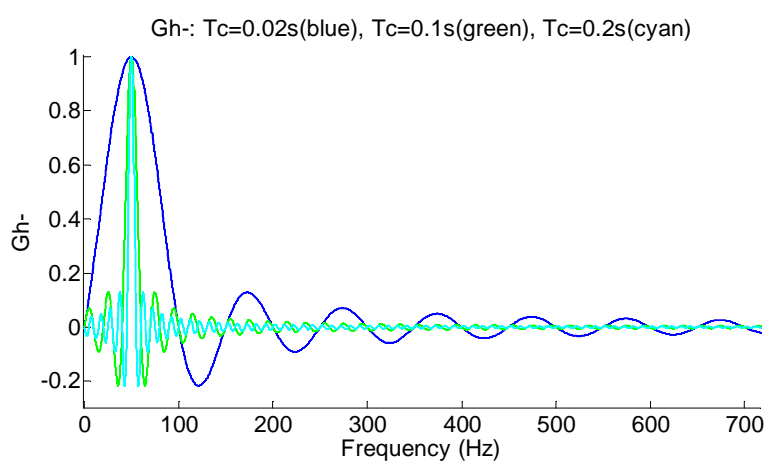

Fig. 3. Impact of value of $T_{\mathrm{C}}$ on rate $G_{h}^{-}$for different frequencies

Tab. I Parameters of the load voltage and current used in simulation

\begin{tabular}{|c|c|c|}
\hline Variable & Magnitude (p.u.) & Phase \\
\hline $\begin{array}{c}v_{\mathrm{L}}=v_{\mathrm{L} 1}=v_{\mathrm{L} 1}^{+} \\
v_{\mathrm{LP}}\end{array}$ & 1 & 0 \\
\hline$i_{\mathrm{L} 1}^{+}$ & 1 & $-\pi / 2$ \\
\hline$i_{\mathrm{L} 1}^{-}$ & 0.5 & 0 \\
\hline$i_{\mathrm{L} 5}$ & 0.2 & 0 \\
\hline
\end{tabular}

We see that, especially for frequencies $\langle 0,100 \mathrm{~Hz}\rangle$, the term $G_{\mathrm{h}}{ }^{-}$is dominating over $G_{\mathrm{h}}{ }^{+}$due to its denominator which is greater than that of $G_{\mathrm{h}}{ }^{+}$in this frequency range. It needs to be emphasized that the values of $G_{\mathrm{h}}{ }^{+}, G_{\mathrm{h}}{ }^{-}$for some specific frequency $\omega_{\mathrm{h}}$ represent the magnitudes of two additional components in (9) with the frequencies $\left(\omega_{\mathrm{h}}+2 \omega\right),\left(\omega_{\mathrm{h}}-2 \omega\right)$, respectively.

Let us demonstrate the use of the GNP strategy presented above on an example of the three phase unbalanced non-sinusoidal system with the load current $\boldsymbol{i}_{\mathrm{L}}$ that contains, in addition to the active current $\boldsymbol{i}_{\mathrm{La}}$, also the reactive current $i_{\mathrm{L} 1 \mathrm{r}}$ associated with the fundamental harmonic only, the fundamental harmonic unbalanced current $i_{\mathrm{L} 1 \mathrm{u}}$, and the harmonic current $\boldsymbol{i}_{\mathrm{Lh}}$.

Figs. 4-6 show the results of the simulation of a model based on (1)-(5) with $v_{\mathrm{LP}}=v_{\mathrm{L} 1}\left(v_{\mathrm{LP}}\right.$ is selected as the fundamental positive sequence component), $T_{\mathrm{C}}=5 T=0.1 \mathrm{~s}$, and with the parameters of the fundamental positive sequence components $v_{\mathrm{L} 1}^{+}, i_{\mathrm{L} 1}^{+}$, fundamental negative sequence component $\boldsymbol{i}_{\mathrm{L} 1}$, and the fifth harmonic current $\boldsymbol{i}_{\mathrm{L} 5}$ declared in Tab. I.

In Fig. 4 we can see how the active current $i_{\mathrm{La}}$ in one phase is separated from $i_{\mathrm{L}}$ when the magnitude of the load current $i_{\mathrm{L}}$ is modulated by the subharmonic signal with the 
magnitude $\Delta I_{\mathrm{L}}=0.2$ p.u. and frequency $10 \mathrm{~Hz}$. Due to the phase shift $-\pi / 2$ between $v_{\mathrm{L} 1}$ and $i_{\mathrm{L} 1}^{+}$the current component $i_{\mathrm{La}}$ has the magnitude $\sqrt{2} / 2$ p.u. Because $T_{\mathrm{C}}$ $=5 T=0.1 \mathrm{~s}$ is just the cycle period of the subharmonic frequency $10 \mathrm{~Hz}$, the extracted active current does not contain any subharmonic component and, of course, any harmonic one as well.

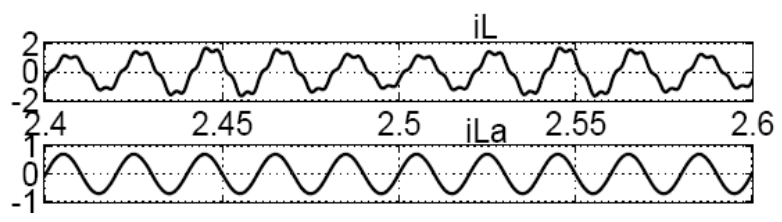

Fig. 4. Extraction of active current from load current $\boldsymbol{i}_{\mathrm{L}}$ specified by Tab. I and additionally modulated by the subharmonic signal with the magnitude $\Delta I_{\mathrm{L}}=0.2$ p.u. and frequency $10 \mathrm{~Hz}$

In Fig. 5 we can see the extraction of the active current $i_{\mathrm{La}}\left(T_{\mathrm{C}}=5 T=0.1 \mathrm{~s}\right)$ from the load current $\boldsymbol{i}_{\mathrm{L}}$ in one phase when the magnitude of the load current $i_{\mathrm{L}}$ specified in Tab. 1 is modulated additionally by the white noise signal with the power spectral density 0.001875 and the correlation time of the noise 0.002 . We see that the load current imitates fairly a waveform with a non-periodic stochastic character like that produced for example by an Electrical Arc Furnace (EAF).

The active current $\boldsymbol{i}_{\mathrm{La}}$ is harmonic free, balanced and in phase with the source voltage $v_{\mathrm{L}}$.

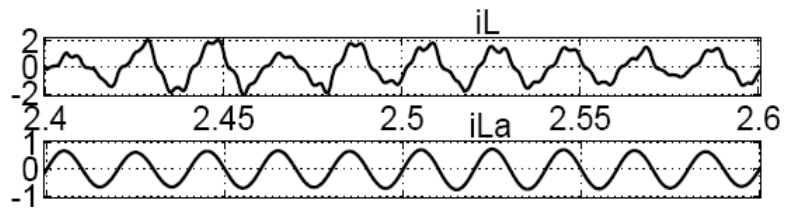

Fig. 5. Extraction of active current from load current $\boldsymbol{i}_{\mathrm{L}}$ specified by Tab. I and additionally modulated by white noise signal with power spectral density 0.001875 and correlation time of noise 0.002

Finally, Fig. 6 presents the results of the extraction of the active current $i_{\mathrm{La}}$ when the additional current interharmonics $(104,117,134$, and $147 \mathrm{~Hz})$ specified by [18] are superimposed to the components of the load current characterized by Tab. I. Again, this non-periodic current $i_{\mathrm{L}}$ imitates a current waveform produced, for example, by the EAF.

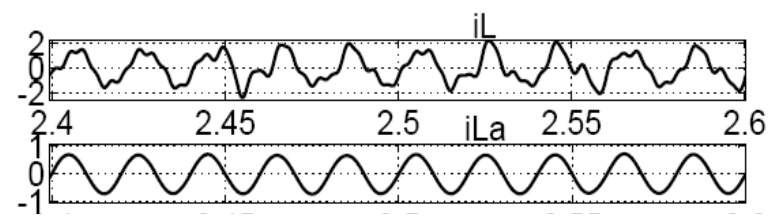

Fig. 6. Extraction of active current from load current $\boldsymbol{i}_{\mathrm{L}}$ with superimposed interharmonics $(104,117,134$, and $147 \mathrm{~Hz}$ ) specified by [18]

It is evident that if the non-active load current $\boldsymbol{i}_{\mathrm{Ln}}=\boldsymbol{i}_{\mathrm{L}^{-}}$ $i_{\mathrm{La}}$ is completely compensated for by a parallel compensator, only the active load current $\boldsymbol{i}_{\mathrm{La}}$ is exchanges with the source, i.e. $i_{\mathrm{S}}=i_{\mathrm{La}}$.

The choice of the value of $T_{\mathrm{C}}$ has a great influence on the quality of the compensation of non-periodic current components. The values of $T_{\mathrm{C}}=(5-10) T$ are high enough to compensate sufficiently for especially the interharmonics with frequencies above $100 \mathrm{~Hz}$. The thing is that interharmonics can be more troublesome than harmonics and voltage fluctuations caused by a combination of interharmonics can cause voltage fluctuations in addition to waveform distortions, resulting in light flicker [12]. As for subharmonics, the lower their frequency is, the higher the value of $T_{\mathrm{C}}$ should be for a sufficient compensation, Fig. 1. The full compensation of the subharmonic with the frequency $\Delta \omega$ needs the averaging time interval $T_{\mathrm{C}}=2 \pi / \Delta \omega$ which, on the other hand, restricts the compensation dynamics in case of transient processes [17]. Another thing is that the energy storage requirement on a power electronics-based compensator is higher for lower $T_{\mathrm{C}}$. That is why, a proper balance between a source current quality in steady states as well as in transients and energy storage requirements should be ensured for concrete conditions.

\section{Parallel active power filter compensation}

The three phase power system was simulated in the Matlab/Simulink ${ }^{\mathrm{TM}}$ environment. The parallel APF (Active Power Filter) was based on the PWM (Pulse Width Modulated) converter. The converter was modeled as a 4-level Capacitor Clamped Inverter (CCI) working with the sampling frequency $1600 \mathrm{~Hz}$. The converter reference current was $i_{\mathrm{CCI}}{ }^{*}=i_{\mathrm{L}}-\boldsymbol{i}_{\mathrm{La}}$.

The nominal line-to-line voltage of the grid was 10 $\mathrm{kV}_{\mathrm{RMS}}$, without any disturbances. The parameters of the $400 \mathrm{kVA}$ load, modeled as the three phase system of current sources, are in Tab. II.

Tab. II Parameters of non-linear load

\begin{tabular}{|c|c|c|}
\hline $\begin{array}{c}\text { Current } \\
\text { component }\end{array}$ & Value in phase & $\begin{array}{c}\text { Current vector } \\
\text { phase shift }\end{array}$ \\
\hline $\boldsymbol{i}_{\mathrm{L} 1}^{+}$ & $I_{\mathrm{N}}=23.1 \mathrm{~A}_{\mathrm{RMS}}$ & $-\pi / 2$ \\
\hline $\boldsymbol{i}_{\mathrm{L} 1}$ & $0.5 I_{\mathrm{N}}$ & 0 \\
\hline $\boldsymbol{i}_{\mathrm{L} 5}$ & $0.2 I_{\mathrm{N}}$ & 0 \\
\hline $\boldsymbol{i}_{\mathrm{L} 7}$ & $0.15 I_{\mathrm{N}}$ & 0 \\
\hline
\end{tabular}

In Fig. 7 we see the waveforms of the grid voltage $v_{\mathrm{L}}$, load current $\boldsymbol{i}_{\mathrm{L}}$, and grid current $\boldsymbol{i}_{\mathrm{S}}$ after compensation in all three phases. The magnitude of the load current $i_{\mathrm{L}}$ with components declared in Tab. II was additionally modulated by the subharmonic signal with the magnitude $\Delta I_{\mathrm{L}}=0.2$ p.u. and frequency $5 \mathrm{~Hz}$. We see that there is a phase shift between the grid voltage and the load current which is not the case for the grid current. Also the magnitudes of the grid currents in all three phases are approximately the same, although the load current is, due to the presence of the negative component $i_{\mathrm{L} 1}$, highly unbalanced. But, due to the choice $T_{\mathrm{C}}=5 T$, a significant part of the subharmonic component with the frequency 5 $\mathrm{Hz}$ is still present in the grid current in accordance with the results presented in Fig. 1. The full compensation of this current could be obtained by setting $T_{\mathrm{C}}=10 T$. 

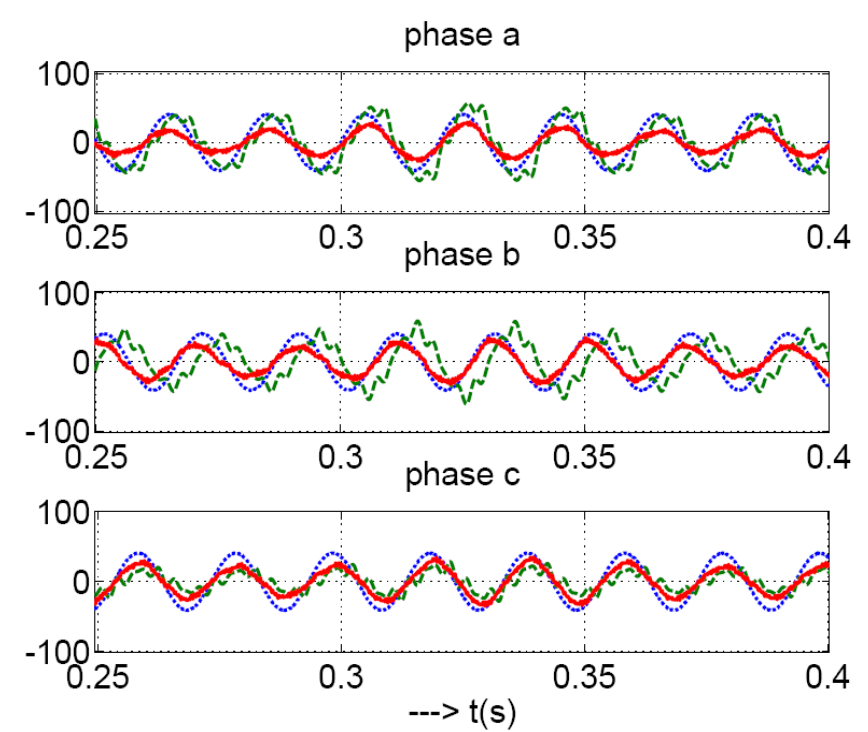

Fig. 7. Waveforms of grid voltage $v_{\mathrm{L}}$ (dotted blue curve), load current $\boldsymbol{i}_{\mathrm{L}}$ (dashed green curve), and grid current $\boldsymbol{i}_{\mathrm{S}}$ (full red curve) after compensation in all three phases. The magnitude of load current $\boldsymbol{i}_{\mathrm{L}}$ with components declared in

Tab. II was modulated by subharmonic signal with magnitude $\Delta I_{\mathrm{L}}=0.2$ p.u. and frequency $5 \mathrm{~Hz}$

Recently, a three-phase four-leg unified series-parallel active filter system compensating for both periodic and non-periodic disturbances using the GNP theory has been presented [19].

\section{Conclusion}

A principal of usage of the generalized non-active power theory for the parallel compensation of periodic and non-periodic (subharmonic, interharmonic) current disturbances is presented in the paper. A non-linear unbalanced load generating periodic as well as nonperiodic stochastic currents connected to an unsymmetrical non-sinusoidal voltage source is considered.

The impact of the value of $T_{\mathrm{C}}$ on the rate $I_{\mathrm{La}} / I_{\mathrm{L}}$ for different frequencies has been studied in the frequency domain $\left(I_{\mathrm{La}}\right.$ is a residuum of the load current magnitude $I_{\mathrm{L}}$ remaining in the active current after the applying GNP strategy). It was found that especially the interharmonic current components above $100 \mathrm{~Hz}$ are sufficiently suppressed for $T_{\mathrm{C}}=(5-10) T$. As for subharmonics, the lower their frequency is, the higher the value of $T_{\mathrm{C}}$ should be for a sufficient compensation. On the other hand, the compensation dynamics in case of transient processes is becoming worse for $T_{\mathrm{C}}$ increasing.

The effectiveness of the generalized non-active power theory to mitigate non-periodic current disturbances is demonstrated on the example of a reactive, unbalanced load current with the $5^{\text {th }}$ harmonic and several interharmonic components, additionally modulated either by the subharmonic component or the white noise signal by the simulations in the time domain.

\section{References}

[1] H. Akagi, Y. Kazanawa, A. Nabae: Instantaneous reactive power compensators comprising switching devices without energy storage components. IEEE Trans. Ind. Appl., Vol. IA-20, No. 3, pp. 625-630, May/June 1984.

[2] W. le Roux, J. D. van Wyk: Evaluation of Residual Network Distortion during Compensation According to the "Instantaneous Power Theory". ETEP, Vol. 8, No. 5, pp. 337-344, September/October 1998.

[3] P. Salmerón, J. C. Montaño: Instantaneous power components in polyphase systems under nonsinusoidal conditions. Proc. Inst. Elect. Eng. Sci. Meas. Tech., Vol. 143, No. 2, March 1996.

[4] A. Horn, L. A. Pittorino, and J. H. R. Enslin: Evaluation of active power filter control algorithms under non-sinusoidal and unbalanced conditions. Proc. $7^{\text {th }}$ Int. Conf. Harmonics and Quality Power, Oct. 16-18, 1996, pp. 217-224.

[5] H. Kim, F. Blaabjerg, B. Bak-Jensen, J. Choi: Instantaneous Power Compensation in Three-Phase Systems by Using $p$ $q-r$ Theory. IEEE Trans. on Power Electronics, Vol. 17, No. 5, pp. 701-710, September 2002.

[6] M. Depenbrock, H. Ch. Skudelny: Dynamic Compensation of Non-Active Power Using the FBD Method - Basic Properties Demonstrated by Benchmark Examples. ETEP, Vol. 4, No. 5, pp. 381-388, September/October 1994.

[7] A. Firlit: Current's Physical Components Theory and $p-q$ Power Theory in the Control of the Three-Phase Shunt Active Power Filter. Electrical Power Quality and Utilisation, Journal Vol. XIII, No. 1, pp. 59-66, 2007.

[8] L. S. Czarnecki, S. E. Pearce: Compensation Objectives and CPS - Based Generation of reference Signals for Shunt Switching Compensator Control. IET on Power Electronics, March 2008, pp. 1-11.

[9] A. Bracale, G. Carpinelli, D. Lauria, Z. Leonowicz, T.Lobos J. Rezmer: On Some Spectrum Estimation Methods for Analysis of Non-stationary Signals in Power Systems, Part I: Theoretical Aspects, Part II: Numerical Applications. ICHQP 2004.

[10] T. Tarasiuk: Hybrid Wavelet-Fourier Method for Harmonics and Harmonic Subgroups Measurement-Case Study. IEEE Trans. on PD, Vol. 22, No. 1, Jan. 2007, pp. 417.

[11] A. Testa, M. F. Akram, R. Burch, G. Carpinelli, G. Chang, V. Dinavahi, C. Hatziadoniu, W. M. Grady, E. Gunther, M. Halpin, P. Lehn, Y. Liu, R. Langella, M. Lowenstein, A. Medina, T. Ortmeyer, S. Ranade, P. Ribeiro, N. Watson, J. Wikston, and $\mathrm{W}$. Xu: Interharmonics: Theory and Modeling. IEEE Trans. on PD, Vol. 22, No. 4, Oct. 2007, pp. 2335-2348.

[12] J. Yong, T. Tayjasanant, W. Xu, and C. Sun: Characteri zing Voltage Fluctuations Caused by a Pair of Interharmonics: IEEE Trans. on PD, Vol. 23, No. 1, Jan. 2008, pp. 319-327.

[13] A. Pizzo, V. M. Moreno: Estimation of Electrical Power Quantities by Means of Kalman Filtering. Source: Kalman Filter: Recent Advances and Applications, Book edited by Victor M. Moreno and Alberto Pigazo, ISBN 978-953-307000-1, pp. 584, April 2009, I-Tech, Vienna, Austria.

[14] T. Lachman, A. P. Memon, T. R. Mohamad, Z. A. Memon: Detection of Power Quality Disturbances Using Wavelet Transform Technique. International Journal for the Advancement of Science \& Arts, Vol. 1, No. 1, 2010.

[15] G. W. Chang, C. I. Chen: An Accurate Time-Domain Procedure for Harmonics and Interharmonics Detection. IEEE Trans. on PD, Vol. 25, No. 3, Sept. 2010, pp. 17871795 . 
[16] F. Z. Peng, L. M. Tolbert: Compensation of Non-Active Current in Power Systems-Definitions from Compensation Standpoint. IEEE Power Eng. Society, Summer Meeting, July 15-20, Seattle, USA, 2000, pp. 983-987.

[17] L. M. Tolbert, Y. Xu, J. Chen, F. Z. Peng, J. N. Chiasson: Application of Compensators for Non-Periodic Currents. IEEE PES Conference (PESC), Acapulco, Mexico, 2003.

[18] IEEE Interharmonic Task Force, CIGRE 36.05/CIRED 2 CC02 Voltage Quality Working Group, Interharmonics in power systems, 1997.

[19] M. Ucar, S. Ozdemir, E. Ozdemir: A four-leg unified series-parallel active filter system for periodic and nonperiodic disturbance compensation. Electric Power Systems Research (2011), doi: 10.1016/j.epsr.2011.01.001.

\section{Appendix}

The load current $i$ (7) consists of three components: the fundamental, subharmonic, market here as a non-periodic component (because the non-periodic current means here a current whose frequency in not an integer multiple of the fundamental frequency), and harmonic one. The calculated active current $i_{\mathrm{a}}$ (8) contains then the following three components $i_{2}, i_{\text {anp }}, i_{\text {ah }}$

$$
i_{2}=\frac{\sqrt{2}}{T_{\mathrm{C}}}\left[-\frac{I}{2 \omega} \sin 2 \omega \tau\right]_{t-T_{\mathrm{C}}}^{t} \sin \omega t
$$

$i_{\text {anp }}=\frac{\sqrt{2}}{T_{\mathrm{C}}}\left[\begin{array}{l}-\frac{\Delta I}{\Delta \omega} \cos \Delta \omega \tau+\frac{\Delta I}{2(2 \omega+\Delta \omega)} \cos (2 \omega+\Delta \omega) \tau- \\ -\frac{\Delta I}{2(2 \omega-\Delta \omega)} \cos (2 \omega-\Delta \omega) \tau\end{array}\right]_{t-T_{\mathrm{C}}}^{t}$

$\sin \omega t$

$i_{\mathrm{ah}}=\frac{\sqrt{2}}{T_{\mathrm{C}}}\left[\frac{-I_{\mathrm{h}}}{\omega+\omega_{\mathrm{h}}} \sin \left(\omega+\omega_{\mathrm{h}}\right) \tau+\frac{I_{\mathrm{h}}}{\omega-\omega_{\mathrm{h}}} \sin \left(\omega-\omega_{\mathrm{h}}\right) \tau\right]_{t-T_{\mathrm{C}}}^{t} \sin \omega t$

The terms marked by the bracket parenthesis, which result from the integration (3), mean the differences of the expressions placed inside between the times $t$ and $t-T_{\mathrm{C}}$.

The components $i_{2}, i_{\text {anp }}, i_{\text {ah }}$ are more or less excluded from the active current component $i_{\mathrm{a}}$ depending on the value of the general averaging time interval $T_{\mathrm{C}}$ and the frequencies $\Delta \omega, \omega_{\mathrm{h}}$. 